\title{
Cardiopulmonary resuscitation in the elderly: patients' and relatives' views
}

\author{
Gillian E Mead and Christopher J Turnbull University Hospital of South Manchester and Arrowe Park \\ Hospital, Upton, Wirral, respectively
}

\begin{abstract}
One hundred inpatients on an acute hospital elderly care unit and 43 of their relatives were interviewed shortly before hospital discharge. Eighty per cent of elderly patients and their relatives were aware of cardiopulmonary resuscitation (CPR). Television drama was their main source of information. Patients and relatives overestimated the effectiveness of CPR. Eighty-six per cent of patients were willing to be routinely consulted by doctors about their own CPR status, but relatives were less enthusiastic about routine consultation. Patients' and relatives' views about the appropriateness of CPR did not differ significantly. Seventeen per cent of patients did not desire CPR. However, 64 per cent of patients were ultimately willing to follow their doctor's advice about the appropriateness of CPR.

The conclusion reached is that mentally competent, elderly patients but not their relatives should be routinely consulted about their own desire for CPR in order to avoid resuscitating patients against their wishes. Further research is required to find out how patients would feel about resuscitation if they were terminally ill or chronically confused, and how carers would feel about resuscitating such patients.
\end{abstract}

\section{Introduction}

CPR was introduced 30 years ago to 'resuscitate the victim of an acute insult' (1). Since then the scope of CPR has widened so that any patient who suffers a cardiac arrest in hospital is a potential candidate for CPR. It is now accepted that CPR is an inappropriate intervention for certain patients, for example, those with terminal malignancy. This has led to the development of 'Not for CPR' orders. In most hospitals the consultant is ultimately responsible for deciding whether or not a patient should be resuscitated.

In 1991, a relative complained to the Health Service Commissioner that a 'Not for CPR' decision had been documented in his elderly mother's

\section{Key words}

Cardiopulmonary resuscitation; CPR; elderly. medical notes without first consulting him. His mother was eventually discharged home. This case was brought to the attention of the Chief Medical Officer who wrote to all doctors emphasising that the consultant's CPR policy should be understood by all his staff (2). In March 1993, the British Medical Association and the Royal College of Nursing published guidelines on resuscitation (3). The consultant's role in making the final CPR decision was emphasised, but it was suggested that in certain circumstances it might be appropriate to discuss CPR with patients and relatives. Since then, there has continued to be much discussion in the literature about whether elderly patients should be involved in deciding upon their own CPR status (4-6). No research to date has systematically studied relatives' views on CPR, although some authors have suggested that relatives should be involved in CPR decision-making $(7,8)$. The purpose of this study was to find out whether elderly patients and their relatives were aware of the CPR procedure, whether or not they wished to be consulted about CPR, and whether or not they would desire CPR in the event of a cardiac arrest.

\section{Methods}

All inpatients under the care of five consultant geriatricians at Arrowe Park Hospital were assessed just prior to their discharge over a period of forty-five consecutive days. Patients who died were therefore not included in the study. Patients were sent a letter one day before the planned assessment, asking if they would participate in the survey. If they were willing, personal details (age, sex, living circumstances and level of independence) were collected, and the doctor's decision regarding CPR was recorded. A patient's level of dependence was classified as follows: a) fully independent in all aspects of activities of daily living (ADL), b) Some help with ADL, c) dependent on others in most aspects of ADL. Patients with an abbreviated mental test score (9) of less than 7, and those with a major depressive illness (DSM III criteria) were excluded. Eligible patients were given a detailed description of the CPR procedure (see appendix). Each patient 


\section{Figure 1}

Source of knowledge about CPR

\begin{tabular}{l|c|c|c|c|}
\hline & Television & $\begin{array}{c}\text { Been } \\
\text { taught }\end{array}$ & $\begin{array}{c}\text { Seen/ } \\
\text { discussed }\end{array}$ & $\begin{array}{c}\text { Books/ } \\
\text { newspapers }\end{array}$ \\
\hline Patients & $48(55 \%)$ & $11(12 \%)$ & $14(16 \%)$ & $15(17 \%)$ \\
\hline Relatives & $29(56 \%)$ & $8(15 \%)$ & $14(27 \%)$ & $1(2 \%)$ \\
\hline
\end{tabular}

completed a questionnaire in the presence of the researcher. Arrangements were made (with the patient's consent) to interview his or her relative separately on the relative's next visit to hospital. The same written explanation of CPR was given, and the same questionnaire was completed.

Results were analysed by the Chi squared test. A 'p' value of less than 0.05 was considered statistically significant. Patients and relatives who answered 'don't know' or 'don't mind' were excluded from the statistical calculations.

One hundred and thirty patients were assessed. Thirty were excluded; of these 30, 21 were confused, 4 were depressed and 5 refused. One hundred eligible patients were questioned. The mean patient age was 81.6 years, range $72-95$, SD 4.9 . Sixty-one per cent of patients lived alone. Sixty-six per cent were women. Forty-three relatives were interviewed. Of these, 10 were spouses, 24 were sons or daughters, two were grandchildren, three were nieces, two were daughters-in-law and two were brothers.

\section{Results}

Eighty per cent of patients had heard about CPR. Thirty-seven relatives ( 86 per cent) had heard about CPR. No significant difference. Chi squared 0.739 , $\mathrm{p}>0 \cdot 1$.

The source of knowledge for those aware of CPR is shown in figure 1 . Some had heard about CPR from more than one source. The main source of knowledge was television for example Casualty, fimmies, 999 and Flying Doctors. Significantly fewer relatives had read about CPR but the same proportion had seen it on television and had been taught it, for example, in the Armed Forces, in $\vec{P}$ industry or on first aid courses. Chi squared $8.76 \vec{t}$ Degrees of Freedom (DF) $3 p<0.05$.

The perceived success rate of CPR in elderl产 patients in general is shown in figure 2. Patients and relatives overestimated the effectiveness of CPR There was no significant difference between patients.and relatives' knowledge about the effectiveness of CPR. Chi squared 2.24, DF 4, not significant.

The response to the question: If you were admitted to hospital again, would you like to be consulted by the doctor about whether or not this CPR procedure should be performed on you? is shown in figure 3 ('You' refers to the patient). Thirty-five per cent of patients positively desiredo routine consultation about CPR, which fiṣ significantly higher than the number of relaties positively desiring consultation. Chi squared $7 \cdot 5$ DF $1, p<0 \cdot 01$. Two-fifths of relatives, ie 39 per cent did not desire consultation with doctors, wherea\& only 14 per cent of patients did not desire consultation.

The patients' response to the question: Would you like your relative to be consulted? is shown in figure 4. Forty-five per cent of patients wanted theif relatives to be consulted, which is significantl $\dot{\mathrm{K}}$ higher than the number of relatives desirin艿 consultation. Chi squared 5.90, p $<0.05$. However nearly a quarter of patients ( 23 per cent) did noe want their relative consulted.

The response to the question: If you were consulted, would you like CPR performed on you? is shown in figure 5 . Those patients and relatives in table 3 who did 'not desire consultation' were not asked this question. There was no significan difference between the patients' and relatives' desire

\section{Figure 2}

Perceived success rate of CPR

\begin{tabular}{l|c|c|c|c|c|c|}
\hline & Always & Mostly & Sometimes & Occasionally & Never & Don't know \\
\hline Patients & $6(6 \%)$ & $52(52 \%)$ & $12(12 \%)$ & $6(6 \%)$ & $1(1 \%)$ & $13(13 \%)$ \\
\hline Relatives & $1(2 \%)$ & $22(51 \%)$ & $8(19 \%)$ & $2(5 \%)$ & $0(0 \%)$ & $10(23 \%)$ \\
\hline
\end{tabular}




\section{Figure 3}

Patients' and relatives' desire to be consulted

\begin{tabular}{l|c|c|c}
\hline & Yes & Don't mind & No \\
\hline Patients & $35(35 \%)$ & $51(51 \%)$ & $14(14 \%)$ \\
\hline Relatives & $11(26 \%)$ & $15(35 \%)$ & $17(39 \%)$ \\
\hline
\end{tabular}

for CPR. Chi squared $1 \cdot 41, p>0 \cdot 1$. Doctors would have resuscitated 99 per cent of patients in the event of a cardiac arrest, which is significantly higher than the number of patients desiring CPR. Chi squared $15 \cdot 7, p<0 \cdot 001$. Almost one fifth (18 per cent) of those patients questioned would not desire CPR in the event of a cardiac arrest, and the ratio of patients to doctors refusing CPR was 15 to 1 .

The answer to the question: Who should make the final decision about whether or not the patient should be resuscitated? is shown in figure 6 . Sixtyfour per cent of patients wanted the doctor to make the final CPR decision. Thirty-seven relatives (86 per cent) wanted the doctor to make the final decision, which is significantly higher than the number of patients who wanted the doctor to decide. Chi squared 5.97, $\mathrm{p}<0.05$.

The characteristics of those refusing CPR and those desiring CPR is shown in figure 7. There was no significant difference in age, sex and level of dependence between those patients desiring CPR and those refusing CPR.

\section{Discussion}

Most of those questioned were interested in the contents of the survey. There was no evidence after close observation by the nursing staff that any patient suffered adverse psychological sequelae as a result of discussing CPR. This confirms the findings of a large study of patients attending hospital for outpatient surgery (10). However, previous studies have shown that discussing CPR with other groups of patients, such as those who are terminally ill, may cause considerable distress (11).

Eighty per cent of patients and relatives had heard of CPR. This is higher than the percentage aware in a study in 1986 (12). The difference is possibly accounted for by the advent of new television drama series, which are the main source of information about CPR. Patients and relatives overestimate the effectiveness of CPR. The majority think that CPR is 'mostly successful'. This confirms the findings of previous studies (13). The reported success rate of CPR in the elderly ranges from 3.4 per cent (14) to 15 per cent $(15,16)$, and is lower in patients with multisystem disease. Bedell studied the outcome of CPR in almost 300 cardiac arrests in Boston (17). Overall, 14 per cent of patients survived until discharge, but no patient with acute stroke, sepsis or pneumonia survived. This raises the interesting question about whether the effectiveness of CPR in television drama is artificially high, or whether television drama is misinterpreted by patients and relatives.

Should patients be routinely consulted about their own desire for CPR? Arguments from this study in favour of routine consultation are as follows: Firstly, 35 per cent of patients positively desired routine consultation with doctors, and an additional 51 per cent were willing to be routinely consulted about CPR. Similar results were obtained by Gunasekera (12). Secondly, there was a significant proportion of patients who declined CPR. This group of patients did not differ significantly in age, sex or level of dependence. Therefore, the only reliable way to identify patients who do not desire CPR is to ask all patients their opinion about CPR. If this were done routinely, it would avoid resuscitating patients against their will. Reasons for declining CPR included the following: 'When my time's come, it's come'; 'God should decide'; 'I just want to go quietly' and 'I've had my threescore years and ten'.

Are there any problems with this approach? Firstly, it is difficult to know when the most appropriate time would be to consult patients. In this survey the patients were questioned just before discharge to avoid the potential problem that the patient's CPR

\begin{tabular}{|l|c|c|c|}
\hline \multicolumn{4}{|c|}{ Figure 4 } \\
\hline & Patients' desire for relative to be consulted \\
\hline Patients & $45(45 \%)$ & Don't mind & No \\
\hline
\end{tabular}




\section{Figure 5}

Patients', relatives' and doctors' desire for CPR

\begin{tabular}{l|c|c|c|cc}
\hline & Yes & No & Don't know & Total & $\begin{array}{c}0 \\
\overrightarrow{7}\end{array}$ \\
\hline Patients & $63(73 \%)$ & $15(18 \%)$ & $8(9 \%)$ & $86(100 \%)$ & $\frac{0}{0}$ \\
\hline Relatives & $21(81 \%)$ & $2(8 \%)$ & $3(11 \%)$ & $26(100 \%)$ & $\frac{0}{0}$ \\
\hline Doctors & $99(99 \%)$ & $1(1 \%)$ & $0(0 \%)$ & $100(100 \%)$ & $\frac{0}{0}$ \\
\hline
\end{tabular}

decision may have been different from the doctor's CPR decision during that particular admission. Patients could be consulted at an outpatient visit or when they visit their general practitioners, but it may be difficult for patients to predict in advance how they would actually feel if they were admitted to hospital. The most logical time to consult patients is when they are first admitted. However, as many patients in this survey pointed out, they may be confused, in pain or simply feeling too unwell to make the decision. A compromise would be to consult patients when they are first seen by the consultant on his ward round. After a general discussion about diagnosis and management, the consultant could mention the hospital's CPR policy and the patient would have the opportunity to refuse CPR.

Are there any occasions when discussion of CPR with patients is not appropriate? Firstly, confused patients may not understand the implications of accepting or refusing CPR, and it would be wrong to burden them with the responsibility of making that decision. In this survey, patients with an abbreviated, mental test score of less than 7 were excluded. This was based on the results of our pilot study which showed that patients with scores of less than 7 did not appear to understand the concept of CPR. Secondly, discussion of CPR with severely depressed patients may be inappropriate. Symptoms of depression in the elderly include recurrent thoughts of death or suicide. If depressed patients refuse CPR, it may be a symptom of their depressive illness and not a reflection of their true feelings about CPR. The implication of this is that all elderly patients should have some form of cognitive assessment on admission to hospital to identify those who are confused or depressed. This is good clinical practice whether $\overrightarrow{\mathrm{g}}$ not patients are subsequently consulted about CPR

Should all patients who are not confused depressed be consulted about CPR? The success rate of CPR depends on the underlying medical problem (17). It is a commonly accepted principles that physicians have no obligation to provide, ang patients have no right to demand, medical treatment of no demonstrable benefit (18). For example doctors would not offer chemotherapy to a patiegt with terminal cancer who was unlikely to bene from such treatment. In the same way doctors should not offer CPR to those patients who would not respond to resuscitation (19).

Seventy-three per cent of those patientis questioned would have wanted CPR in the ever 8 a cardiac arrest. However, a similar study in Iretind showed that 74 per cent of patients would refure CPR (20). This may reflect the predominant Roman Catholic religion of the patients in tide survey, or the fact that the author's description of CPR emphasised the possible need for ventilation and intensive care following effective resuscitation The influence of religion on CPR preferences $\overline{\phi S}$ unclear, with one study showing that Catholics we more likely to want resuscitation (13).

Doctors had decided to resuscitate 99 per cent patients in this survey. In our hospital an 'opt out?' CPR policy exists, so that a patient is 'for CPR' unlegs otherwise stated in the case notes. It is therefore possible that some patients unsuitable for CPR would have been resuscitated by default. Some hospitats operate an 'opt in' CPR policy which means that some patients may be inappropriately denied CPR (2 IN/ This emphasises the need for a clearly documented

\section{Figure 6}

Who should make the final CPR decision?

\begin{tabular}{|c|c|c|c|c|}
\hline & Doctor & Patient & Relative & Don't know \\
\hline Views of patients & $64(64 \%)$ & $19(19 \%)$ & $14(14 \%)$ & $3(3 \%)$ \\
\hline Views of relatives & $37(86 \%)$ & $2(5 \%)$ & $4(9 \%)$ & $0(0 \%)$ \\
\hline
\end{tabular}




\section{Figure 7}

1) Age:

2) Males: Females:

Chi squared $2.99 \mathrm{p}>0.05$

3) Living alone

Living with relatives

Nursing/residential homes

Chi squared $0 \cdot 127 \mathrm{p}>0 \cdot 10$

4) Fully independent

Some help with ADL

Dependent

Chi-squared $0 \cdot 135 p>0 \cdot 10$

\section{Patients desiring CPR}

81 years ( 72 to 95 )

$23(37 \%)$
$40(63 \%)$

$36(57 \%)$

$24(38 \%)$

$3(5 \%)$

$36(57 \%)$

$18(29 \%)$

$9(14 \%)$
Patients refusing CPR

82 years ( 73 to 89 )

\author{
$2(13 \%)$
}

$13(87 \%)$

$8(53 \%)$

$6(40 \%)$

$1(7 \%)$

$8(53 \%)$

$5(33 \%)$

$2(13 \%)$
CPR decision to be made for each patient. In our hospital, patients' CPR status is marked by means of a blue spot against their names on a central board by the nurses' station. Another interesting point is whether patients would still want CPR if they were aware of the true success rate. Informal discussion with patients at the end of this survey suggested that the low success rate would make no difference to their decision.

Should relatives be routinely consulted about CPR? In our survey, 45 per cent of patients wanted their relative to be consulted, and an additional 32 per cent were willing for their relative to be consulted. However, relatives were significantly less enthusiastic about routine consultation, preferring the doctor to make the final CPR decision. Thus it is difficult to justify always consulting the relative. However, there are times when consulting relatives may be important. If a patient is too confused to discuss CPR, then a surrogate view could be sought, for example, from a close relative (22).

The majority of patients and relatives wanted the doctor to make the final CPR decision. This appeared to reflect their feeling that the doctor was in the best position to make the most objective decision. Comments from patients included 'the doctor knows best' and 'the doctor is paid to make that decision'. This does not imply that patients should not be consulted, rather that the decision should be a joint one between doctor and patient.

\section{Recommendations}

Doctors should consider discussing CPR with mentally alert elderly patients in order to identify in advance those who would not desire CPR in the event of a cardiac arrest. Where possible, the final CPR decision should be a joint one between the patient and the doctor. There is no evidence from this study that routine consultation with relatives is indicated, provided that patients understand the implications of desiring or refusing CPR. Doctors and nurses should be aware of the BMA and RCN guidelines on resuscitation. Each hospital should have a clearly documented CPR policy, including a statement of whether the policy is 'opt in' or 'opt out'. Each hospital should have a system to ensure that the CPR status of individual patients is easily accessible to every member of staff who may be responsible for initiating CPR or calling the cardiac arrest team. Doctors and nurses now receive formal training in the medical aspects of resuscitation, such as defibrillation and intravenous drug administration, and many hospitals employ a resuscitation officer. It is therefore necessary to incorporate discussions about the ethical issues surrounding $\mathrm{CPR}$ in undergraduate and postgraduate medical courses for doctors and nurses. CPR should be the subject of group discussions for hospital patients, ex-patients and intending patients and their relatives, alongside other quality-of-life issues. The concept of 'advance directives' needs wider discussion amongst doctors and patients. The possibility of general practitioners discussing CPR in advance with elderly patients needs consideration.

Further studies are required to find out whether the perceived high success rate of CPR increases the likelihood of a patient's desiring CPR, and whether fewer patients would desire CPR if the true success rate were more widely known.

This study focused on the opinions of mentally alert elderly patients who were well enough to be discharged from hospital. Further research is required to ascertain whether the opinions of these patients would differ if they were terminally ill or chronically confused, and whether they would like doctors to seek a surrogate opinion about CPR from their next of kin, close relative or the person appointed to hold power of attorney. Research is also required to find out whether relatives caring for chronically confused patients want to be involved in deciding upon the patient's CPR status, or whether they would prefer to leave the CPR decision to doctors alone. 
Hospital doctors' views about CPR need clarification: Do they find their own hospitals' guidelines on CPR adequate?; Are the BMA guidelines helpful?; Are they willing routinely to discuss CPR with elderly inpatients?

Finally, this study emphasises that despite the thrust of current medical practice to save life, a significant proportion of elderly patients want to end their lives naturally. Further studies are required to find out whether elderly patients want intensive treatment for other life-threatening conditions such as cancer, or whether they would prefer to 'let nature take its course'.

\section{Appendix}

\section{DESCRIPTION OF CPR GIVEN TO PATIENTS AND RELATIVES}

On admission to hospital a full medical assessment of each patient is made. Doctors decide which treatment is appropriate for each patient. Doctors also decide whether or not to resuscitate a patient if he or she has a cardiac arrest. A cardiac arrest means that a patient's heart and lungs suddenly stop working and the patient collapses and becomes unconscious. 'Resuscitation' involves doctors and nurses pumping on a patient's chest, putting him or her on a drip, and if necessary on a breathing machine. A small electric shock applied across the chest may also be needed. The aim is to restart the heart and lungs and revive the patient. The purpose of this questionnaire is to find out how you and your family feel about this resuscitation procedure. It will provide doctors with useful information that will improve patient care in the future.

This questionnaire is confidential and anonymous. It does not imply that you will have a cardiac arrest. It will not in any way affect your treatment now or in the future.

\section{Acknowledgements}

We are grateful to the following Consultant Geriatricians for allowing us to interview their patients: Dr S S Garewal, Dr J Lorains, Dr G Sangster and Dr J Russell; and to Professor M Lye for his helpful comments on the manuscript.

Gillian E Mead, $M A, M R C P$, is a Research Fellow in the Department of Geriatric Medicine at the University of South Manchester. Christopher $\mathcal{F}$ Turnbull, MB, BChir, FRCP, is a Consultant in the Department of Medicine for the Elderly, Arrowe Park Hospital, Upton, Wirral.

\section{References}

(1) Talbot J H, Jude J R, Elam J O. Fundamentals of cardiopulmonary resuscitation. Philadelphia: F A Davis, 1965.
(2) Calman K C, Health Service Commissione Annual report for 1990/1991. Resuscitation policy [letter]. Department of Health, Richmond Hous London, 1991.

(3) A statement from the BMA and the RCN in assoc?? ation with the Resuscitation Council UK. Decision relating to cardiopulmonary resuscitation. 1993 Mar. $\stackrel{\text { f }}{\rightarrow}$

(4) Lubel D D. Resuscitation: a need for a more hone approach. Geriatric medicine 1992; 2, 8: 13.

(5) Smith E M, Hastie I R. Resuscitation status of the elderly. Fournal of the Royal College of Physicians London 1992; 26, 4: 377-379.

(6) Davies K N, King D, Silas J H. Professional attitudês to cardiopulmonary resuscitation in departments $\vec{A}$ geriatric and general medicine. fournal of the Royat College of Physicians 1993; 27, 2: 127-130.

(7) Stewart K, Abel K, Rai G S. Resuscitation decisions. in a general hospital. British medical journal 1990; 30ङ 785.

(8) Dudley N J. Do not resuscitate orders [letter]. British medical journal 1992; 304: 121.

(9) Hodkinson H M. Evaluation of a mental test score fä the assessment of mental impairment in the elderly Age and ageing 1972; 1: 223-238.

(10) Robertson G S. Resuscitation and senility: a study of patients' opinions. fournal of medical ethics 1993; 1\% 104-107.

(11) Schade S G, Muslin H. Do not resuscitate decision泾 discussions with patients. Fournal of medical ethics. 1989; 15: 186-190.

(12) Gunasekera N P R, Tiller D J, Clements LôṬ़ Bhattacharya B K. Elderly patients' views on carefico pulmonary resuscitation. Age and ageing 1986; 364-368.

(13) Schonwetter R S, Teasdale T A, Taffet G, Robinso B E, Luchi $\mathrm{R}$ J et al. Educating the elderl cardiopulmonary resuscitation decisions before and after intervention. Fournal of the American Geriatr $\overrightarrow{8}$ Society 1991: 39: 372-377.

(14) O'Keeffe S, Redahan C, Keane P, Daly K. Age and other determinants of survival after in-hospit cardiopulmonary resuscitation. Quarterly journal medicine 1991: 81: 1005-1010.

(15) Bayer A J, Ang B C, Pathy M S J. Cardiac arrests in geriatric unit. Age and ageing 1985; 14: 271-276.

(16) Gulati R S, Bhan G L, Horan M A. Cardiopulmonary resuscitation in old people. Lancet 1983; 2: 267-26.

(17) Bedell S E, Delbanco T L, Cook E F, Epstein F H. Survival after cardiopulmonary resuscitation in the hospital. New England journal of medicine 1983; 309; 569-576.

(18) Tomlinson T, Brody H. Ethics and communicatio in do-not-resuscitate orders. New England journal $\circledast$ medicine 1988; 318: 43-46.

(19) Blackhall L J. Must we always use CPR? New Englang journal of medicine 1987; 317: 1281-1284.

(20) O'Keefe S T, Noel J, Lavon J N. Cardiopulmonał resuscitation preferences in the elderly. Europed journal of medicine 1993; 2: 33-35.

(21) Liddle J, Gilleard C, Neil A. Elderly patients' and their relatives' views on CPR [letter]. Lancet 19935 342: 1055.

(22) Florin D. 'Do not resuscitate' orders: the need for policy. Fournal of the Royal College of Physicians of London 1993; 27: 135-138. 